\title{
Castros carpetanos de época prerromana
}

\author{
Julián Hurtado Aguña \\ Universidad de Salamanca
}

\section{Resumen}

Este artículo analiza las características de los asentamientos carpetanos y de algunas ciudades mencionadas por las fuentes históricas en el inicio de la conquista romana de este territorio.Las actividades económicas de estos enclaves,su cultura material y su pervivencia en algunos casos en época romana son también objeto de análisis.

\section{Abstract}

This article analyses the characteristics of carpetanian settlements and other preroman cities mentioned by historical sources during the beginning of the roman conquest of this territory. The economic activities of this enclaves, their cultural material,and in some cases, their survival during the roman period are also subject to analysis.

El área carpetana se extendía por un territorio que comprendía una parte importante de la actual Meseta Sur. El límite de este territorio por el sur parece que alcanzaba el Guadiana. En su zona más oriental el límite es más impreciso,en un territorio donde estaban asentados también olcades y celtíberos. En su zona occidental,el área carpetana limitaba con la zona de influencia de la cultura vetona, que viene definida entre otros rasgos por la presencia de esculturas denominadas verracos,así como por una economía de marcado carácter ganadero. Finalmente en su zona septentrional este territorio alcanzaba las estribaciones del Sistema Central.

Las fuentes históricas nos ofrecen algunas noticias acerca de los carpetanos y del territorio que habitaban. Así por Polibio (3, 13, 5) y Livio (21, 5, 2 ), podemos deducir que se encontraban al sur de los vacceos, eran vecinos de los olcades,que se hallarían al este y que el Tajo cruzaba su territorio. Estrabón los sitúa al norte de los oretanos (III, 2, 6) mientras que Plinio dice que habitan junto al río Tajo (III, 19) siendo Toledo "cabeza de la Carpetania” (III, 25). Finalmente Ptolomeo $(2,6,56)$ cita dieciocho ciudades carpetanas de las que Toletum y Complutum están claramente identificadas y el resto son de dudosa localización.

Actualmente la investigación considera que este territorio carpetano, estaba constituido por civitates desarrolladas en si mismas como estados, con lazos culturales comunes, pero que nunca llegaron a unirse en coaliciones políticas de ámbito superior. En este sentido J. Caro Baroja es de la opinión que muchas ciudades carpetanas se encontraban asentadas en riscos y escarpaduras con cuevas naturales o artificiales que servían a la gente de mansiones o habitat. (Caro Baroja, 1981, 282 y 291) Es posible que una de estas ciudades fuera Caraca que fue sometida por Sertorio y cuya población habitaba en cuevas. (Plutarco, Sert. XVII).

La Segunda Edad del Hierro en la submeseta Sur vendrá marcada por la progresiva implantación de la iberización.Este período desde un punto de vista cronológico abarcará en general la segunda mitad del primer milenio. El proceso de iberización de las tierras centrales de la Meseta Sur se da a partir del siglo IV a.C.apareciendo en esta zona cerámicas ibéricas con decoración pintada monócroma y bícroma de tonos rojos y castaños. También la presencia en yacimientos de esta área de algunas cerámicas de importación como las cerámicas áticas de barniz negro procedentes de Mejorada del Campo (Madrid) o el fragmento de barniz rojo de Fuente el Saz del Jarama (Madrid)nos indican la presencia de contactos comerciales con otras zonas del sur y levante peninsular. Estos contactos comerciales 
fueron posibles gracias a la existencia de vías de comunicación de época prerromana.

Entre las novedades técnicas de este período, podemos destacar la introdución del torno de alfarero para la elaboración de cerámica, aunque en los yacimientos carpetanos de esta fase aparecen también numerosos testimonios de cerámica hecha a mano.En el campo de la metalurgía asistimos a la introducción de la siderurgia si bien la presencia de hierro es más bien escasa. Dentro de las técnicas constructivas se debe destacar como novedad el empleo del tapial y los adobes. Aunque el área carpetana recibe las influencias de la zona ibérica, los carpetanos también presentan una importante influencia céltica, que nos permite relacionar esta zona con el área de la Meseta Norte y cuyos rasgos serían entre otros la presencia en los yacimientos de cerámicas incisas y excisas y de determinados tipos de fíbulas o las terminaciones en -briga de algunos nombres de sus ciudades.

Durante la II edad del Hierro,los asentamientos del área carpetana se establecían principalmente en lugares elevados y fácilmente defendibles que dominaban valles y territorios de importancia estratégica. También la inestabilidad provocada en la Península, a raiz de la actividad bélica entre romanos y cartagineses, desde finales del siglo III a.C. provoca que la población se vea en la necesidad de agruparse y buscar refugio en grandes castros defensivos.

Posteriormente la actuación de estos núcleos indígenas frente al fenómeno de la conquista romana, no es desconocida, salvo cuando existen referencias en las fuentes históricas como en el caso de Alce o Toletum. En cualquier caso parece más importante destacar la expansión de pueblos como los celtíberos durante los siglos III-II a.C. en zonas como Carpetania (Blázquez, 1986, 204)que la propia resistencia de los carpetanos al dominio de Roma.

Entre los asentamientos del área carpetana,el Cerro del Ecce Homo, se encuentra próximo a la ciudad de Alcalá de Henares (Madrid). Este lugar dista de esta ciudad unos 3,5 Kms. en dirección sureste. Su situación privilegiada,que ofrecía unas buenas condiciones defensivas, hizo que tuviera una prolongada ocupación desde comienzos de la edad del Bronce hasta la iberización. En este período se ha hallado alguna estructura como una

1. El Cerro de S. Juan del Viso domina la principal vía de comunicaciones, un amplio tramo del Valle que comprendía desde Guadalajara hasta la confluencia del Henares con el Jarama.

2. Concretamente sabemos que varios sondeos realizados en diversas zonas de la Meseta del Cerro en 1978, cabaña datada entre los siglos VII-VI a.C. La estructura de esta cabaña evidencia una desarrollada arquitectura de madera de difícil comparación con otros yacimientos peninsulares. Existen evidencias en este lugar de una continuidad de la población durante la II edad del Hierro, con la presencia en determinados silos de cerámicas pintadas celtibéricas. (Fernández Galiano, 1976, 31) Con posterioridad en el momento que la romanización alcanza esta zona,el cerro del Ecce Homo ya había dejado de existir como poblado.

Otro importante asentamiento de época prerromana era Complutum (Alcalá de Henares, Madrid). La primitiva ubicación de este enclave parece ser el cerro de S. Juan del Viso, ocupado en época republicana. Complutum será en este período un oppidum carpetano de importante extensión y a la vez constituía un centro estratégico que controlaría el cruze de vías del Henares inferior $^{1}$. Este enclave contaba con una vía de comunicación importante hacía el sureste, que salía del cerro en su vertiente sur hacia Torres de la Alameda y comunicaba el valle del Tajo con la costa levantina,dirigiéndose a través de Segóbriga, y Saltigis hacia las ciudades costeras de Valentia, Ilici y C. Nova (Fernández Galiano, 1984, 397). Desconocemos hasta la actualidad la organización urbana de este oppidum, en el que se han documentado cerámicas pintadas de tipo ibérico (Polo, 1995-6, 43). Hasta la actualidad no han aparecido en este asentamiento materiales encuadrables en época republicana, pasándose de las típicas cerámicas pintadas de época celtibérica a las primeras piezas de Terra Sigillata Itálica, datables en época de Augusto.

Posteriormente este inicial asentamiento del Cerro de S. Juan del Viso será progresivamente abandonado y la ciudad se desplazará al llano, donde se instala a partir del siglo I d.C. El tipo de habitat será tras el descenso del cerro, esencialmente villae que aunarán lo residencial y agrícola. Aunque la población comienza desde mediados del siglo I d.C.a descender al llano, a la fértil vega del Henares, el Cerro no se despobló nunca totalmente ${ }^{2}$, quedando restos de época bajoimperial. Las fuentes históricas mencionan este oppidum cuando nos narran la huida de Sertorio hacia Valencia en el año 75 a.C. (Frontino II, 3, 5). También de época sertoriana es un tesorillo de monedas aparecido en la cuesta de Zulema.

documentaron la presencia de una hypocaustum de buena técnica constructiva, que pudiera pertenecer a unas termas públicas, desmontadas a mediados del siglo I d.C., con el fin de trasladar los materiales aprovechables a la zona del valle, nuevo asentamiento de la ciudad. 
Este tesorillo estaba constituido por más de 1500 denarios romanos e ibéricos, de época republicana. Ocultamientos como este se han relacionado con los desequilibrios que han producido los conflictos entre Metelo y Sertorio en el interior peninsular. Parece que la condición de municipio la va a adquirir Complutum en época flavia, cuando al igual que otras ciudades de la Meseta desarrolla un importante programa urbanístico. Ocupará también en este momento una privilegiada situación en la red viaria de la zona central peninsular, siendo mansión de la vía EméritaCaesaraugusta.

Cerca del cerro de S. Juan del Viso, donde se situaba la ciudad de Complutum en época republicana, se encontraba el castro denominado "Salto del Cura", que ocupaba una pequeña extensión de aproximadamente media hectárea. Este castro, cuenta con una superficie aproximada de $90 \times 50$ mts, y está rodeado por un terraplen poco marcado que podría contener un muro. (Blasco, Alonso y Valiente, 1980, 53) Este castro presenta una cultura material definida por la presencia de cerámicas hechas a torno,con pasta de color anaranjado,algunas de ellas decoradas con líneas y bandas horizontales. (Polo, 1995-6, 41) Junto a esta cerámica se ha atestiguado también la presencia de cerámica campaniense.

En la provincia de Madrid se localiza también el yacimiento de Cerro Redondo. Se trata en este caso de un pequeño asentamiento, con total ausencia de arquitectura defensiva, cuya cronología aproximada se fecha entre los siglos IV a III a.C. Su sistema urbanístico presenta estructuras independientes adaptadas a la topografía del terreno, que es un modelo habitual de algunos yacimientos de la Meseta Norte. Este yacimiento se ubica en la cuenca del río Jarama, próximo al puerto de Somosierra. Este poblado está ubicado en un suave promontorio que domina la fértil vega del Jarama, por lo que probablemente su actividad económica estaría enfocada a la producción agrícola. Entre los elementos célticos que aparecen en este yacimiento están las cerámicas estampilladas y una fíbula zoomorfa de caballito. De otra parte la cerámica de bandas y semicírculos concéntricos así como las fíbulas anulares, de timbal nos indican las influencias del área levantina. En este yacimiento también han aparecido tres fragmentos de cerámica importada, dos de los cuales son de barniz rojo y el tercero de cerámica ática (Blasco y Alonso, 1985, 111). Las actividades económicas básicas de este asentamiento eran la agricultura y la ganadería. Respecto a la actividad ganadera parece existir un predominio de ovidos, cápridos y bóvidos. (Blasco y Alonso, 1986-7, 166) El abandono de este asentamiento por parte de sus ocupantes, parece responder a la pobreza material de este yacimiento. (Blasco y Alonso, 1985, 135)

Algunos de estos enclaves carpetanos estaban ubicados en lugares dominantes de gran tamaño y defendidos por importantes recintos amurallados como en el caso del Cerro de la Gavia (Vallecas, Madrid). (Priego, 1980, 95) Este asentamiento situado en la margen izquierda del río Manzanares, ha proporcionado cerámica a torno pintada de tipo celtibérico. Este yacimiento parece que se inicia en el Hierro I y perdura hasta la romanización. (Blasco, Alonso y Valiente 1980, 51) También se sitúa en un lugar estratégico en la orilla izquierda del Manzanares, el yacimiento de Sta Catalina, en el que han aparecido junto a diversos fragmentos de cerámica estampillada, algo de terra sigillata, que nos indica la perduración de este enclave en época romana. (Blasco, Alonso y Valiente, 1980, 54)

En el área próxima a Complutum (Alcalá de Henares, Madrid), en el término municipal de Santorcaz están también documentadas unas estructuras de viviendas,algunas de las cuales presentan forma circular, sobre un cerro amesetado de unas 14 hectáreas de extensión. No parece existir en este asentamiento una planificación de carácter urbanístico. De otra parte existen indicios de la existencia de construcciones, que pudie-ran tener un carácter defensivo. La cronología propuesta para este enclave va desde el siglo II a.C. hasta época augustea. (Polo, 1995-6,41)

También en la actual provincia de Madrid,se localizaba el Castro de la Dehesa de la Oliva, concretamente en la localidad de Patones de Abajo. Este castro de la II edad del Hierro,estaba situado en la ladera sur de la Sierra de Guadarrama. El yacimiento se asienta sobre un cerro con una altura de 902 mts sobre el nivel del mar. Su localización le permitía el control de paso a la sierra norte madrileña. El cerro en el que se localiza es sólo accesible con facilidad por el lado sur donde se levantó una muralla. Este castro controlaba las tierras más rentables para la agricultura, localizadas en torno al valle del Jarama. Una de las actividades económicas de este castro parece que iba dirigida a la extracción de minerales. Este yacimiento se encontraba asentado sobre tres terrazas, ocupando el castro celtibérico la terraza más alta. Se trata de un complejo amurallado con una exténsión aproximada de $1000 \mathrm{mts}$ por 500 . (Muñoz, 1980,59) La muralla falta en aquellas zonas donde existe una defensa natural del terreno. El espesor que presenta es aproximadamente de 1,45 mts. Se ha documentado además de esta muralla, varias manzanas de viviendas, razadas en ángulo recto en lo que podía ser una especie de retícula 
hipodámica. Las edificaciones se sitúan en la mayoría de los casos a ambos lados de las amplias calles de este yacimiento. El tipo de edificación más común en este castro es el de un edificio de planta rectangular, distribuido en tres o cuatro compartimentos. Cada una de estas habitaciones presentaba una funcionalidad diferente.

Entre los diversos tipos cerámicos hallados en este enclave se encuentran las cerámicas de pasta negra y la cerámica Campaniense A, que marca la penetración de las formas de vida romana en el mundo indígena. Entre los materiales que ha proporcionado no abunda la Terra Sigillata, aunque si multitud de ob-jetos metálicos como clavos, agujas y algunas fí-bulas anulares y omegas. (Polo, 1995-6, 42) Este yacimiento se data cronológicamente en el siglo II a.C. Debemos indicar que este asentamiento presenta un importante influjo de la romanización, que se hace patente en su entramado urbanístico y organización interna.

En el noreste de la provincia de Madrid,en las cercanías de la localidad de Redueña, existe un castro celtibérico de gran extensión. Está situado en un cerro de facil defensa y cercano a un curso de agua. La cima se encuentra aterrazada y no cuenta con restos visibles de estructuras. En esta zona se han documentado los restos de cinco cabañas de época celtibérica, distribuidas de forma dispersa y situadas frente al castro de la misma época. La funcionalidad de las mismas nos es desconocida, aunque es probable que en ellas se guardasen las herramientas necesarias para las actividades agrícolas y ganaderas, que se desarrollaban en esta zona. (Alfaro y Martín, 1996, 95) Las cabañas, salvo en un caso son de planta rectangular y cuentan con una superficie pavimentada, realizada a base de pequeños guijarros que son incrustados directamente sobre el nivel natural. Los restos de cerámica aparecida en este enclave son de mala calidad, en su mayoría de cocina. Destacan también en este yacimiento la presencia de un collar de pasta vitrea, así como una fíbula. Son igualmente numerosos los restos de diversos objetos fragmentados de bronce (bolas, varillas, etc). La cerámica aparecida en este enclave así como la fíbula y la cuenta de collar, permiten datar estas estructuras entre los siglos II-I a.C. (Alfaro y Martín, 1996, 96)

Algunos enclaves como Caraca son mencionados por las fuentes históricas a propósito de las luchas entre Sertorio y Metelo en la primera mitad del siglo I a.C. Concretamente las fuentes históricas nos informan que el enclave de los caracitanos fue tomado por Sertorio mediante una habil estratagema (Plut., Sert. 17). También Ptolomeo $(2,6,56)$ menciona a esta ciudad en una lista de ciudades carpetanas. De otra parte el Ravenate sitúa este enclave de Caraca entre Complutum y Segobriga (Saélices). Este asentamiento carpetano se ha intentado localizar en diferentes lugares de Madrid y Guadalajara (Taracena, Carabaña, etc) aunque la más reciente ubicación sitúa este asentamiento en el Cerro de la Virgen de la Muela en Driebes. (Abascal, 1982, 79-81) En este lugar se halló en 1940 un conjunto de joyas, plata y monedas de diversa procedencia, entre ellas denarios romanos, de los cuales el más moderno se puede fechar entre el 119 y el 91 a.C. (Salinas, 1986, 131)

En la provincia de Madrid se localizaba el enclave carpetano de Titulcia. Este asentamiento era un nudo de comunicaciones importante de la Meseta Sur. Cuenta este yacimiento con una necrópolis celtibérica, de la se conservan algunos restos. En este sentido se han hallado fragmentos de cerámica tosca, confeccionada a mano, pertenecientes a una urna cineraria de perfil en"s". (Blasco, Alonso y Valiente, 1980, 51) El ajuar que acompañaba a esta tumba lo componían un par de pinzas de bronce y fue fechado en el siglo III a.C. Esta urna cineraria ha sido localizada en la ladera del asentamiento celtibérico.

En cuanto a los restos de cultura material hallados en este enclave, podemos incluir diversos fragmentos de cerámica pintada celtibérica no figurativa y también cerámica campaniense (Blasco y Alonso, 1983, 128). La presencia de este último tipo de cerámica implica una aproximación al período de la conquista romana. Probablemente Titulcia adquirió su condición de municipio romano en época flavia. Esta opinión es sostenida por R. C. Knapp en base al hallazgo de una inscripción monumental próxima a la ciudad que menciona a un individuo perteneciente a la tribu Quirina. (Knapp, 1992, n.194)

Algunas ciudades como Mantua, aparecen mencionadas por Ptolomeo en su lista de ciudades carpetanas, que aparecen recogidas en el libro II de su Geographia. En esta obra Mantua tiene asignada una longitud de $11^{\circ} 40^{-}$y una latitud de $41^{\circ} 15^{\prime}$, por lo que probablemente se situaría al norte del río Tajo entre Complutum y Titulcia. (Contreras, Jiménez y Martín, 1993, 400) Desconocemos la importancia y dimensiones de esta ciudad en la antigüedad, que no debió ser un punto de interés en la red viaria principal romana. Tradicionalmente se la viene localizando en Villamanta (Madrid) en base a la similitud topónímica y por los restos arqueológicos aparecidos en este lugar (Urbina, 1998, 187). La presencia romana en esta zona parece establecerse en diversos asentamientos en los márgenes del Arroyo Grande. A juzgar por los materiales hallados en estos yacimientos, 
el inicio del poblamiento de este lugar parece iniciarse en el siglo II d.C. continuando hasta época tardía. (Contreras, Jiménez y Martín, 1993, 401).

Otra de estas ciudades de menor entidad citada por Ptolomeo fue Varada. A esta ciudad se le atribuye una emisión de ases ibéricos, con la leyenda "vardus". Según la hipótesis de Fita, Varada se situaría en el despoblado de Valtierra (Arganda) a partir de la relectura del ara de las Ninfas encontrada en este lugar. (Fita, 1917, 352-353) También en la provincia de Madrid, se situaba el enclave de Miaccum. Se piensa que pudo estar localizado en la casa de Campo de Madrid, en el nacimiento del arroyo Meaques. Según el Itinerario de Antonino constituía una mansión de una vía romana que desde Segovia llegaba hasta Titulcia, distando 24 millas de esta última.

Otra de las ciudades carpetanas citadas por Ptolomeo es Ispinum (Ptolomeo 2,6,56). Aunque desconocemos su localización exacta, así como su importacia en la antigüedad, tradicionalmente se la ubica en Yepes (Toledo).

En la provincia de Toledo, se localizaba el enclave celtibérico de El Cerrón ubicado en la comarca de la Sagra, en una localización entre la Cordillera Central y los Montes de Toledo. Ocupa la plataforma superior de un pequeño cerro ovalado de algo menos de 1,5 hectáreas de superficie.La configuración actual del asentamiento celtibérico nos muestra la ocupación más antigua,con dos santuarios superpuestos en las zonas más elevadas del cerro, mientras que el poblado se extiende por toda la plataforma. En la zona del santuario se ha hallado un relieve incrustado en un muro de adobe. La escena presenta la secuencia de dos carros guiados por sendos aurigas $\mathrm{y}$ arrastrados por caballos a los que sigue un glifo. Delante de el segundo carro aparece la figura de un personaje de pie, que levanta su brazo izquierdo. Este relieve es objeto de diversas interpretaciones: podría tratarse de personajes heroizados o divinidades cuyo símbolo fuese el glifo. También podría representar el viaje de dos personajes difuntos al mundo de ultratumba. Este asentamiento carpetano presenta un habitat con estructuras en adobes y materiales bastante iberizados.Entre los materiales aparecidos destaca también la cerámica jaspeada, característica de esta región. (Blasco, 1992, 294)

También en la zona más oriental de la provincia de Toledo, está localizado el yacimiento del Cerro del Gollino. Está situado en una zona limítrofe a la actual provincia de Cuenca. Se trata de un gran castro carpetano de una exténsión superior las 15 hectáreas del que sólo conocemos una pequeña parte. Este yacimiento contaba con un doble recinto amurallado y puede ser considerado como un importante castro similar a otros como Consuegra, Yeles o Mora. Entre los restos cerámicos hallados en este asentamiento, podemos destacar la cerámica de factura indígena con la presencia de grandes recipientes de almacenamiento y toneletes. (Santos, Perea, y Prados, 1990, 315) También es destacable la presencia de cerámica jaspeada y diversos fragmentos de ánforas republicanas. Dentro de las cerámicas de importación abunda la cerámica Campaniense de las formas 1 y 5 de Lamboglia. Entre los diversos objetos metálicos aparecidos en este enclave figuran una espada de filos rectos, un cuchillo, un regatón, una fíbula anular hispánica así como numerosos fragmentos de clavos y remaches. $\mathrm{Pa}$ rece probable que la construcción del recinto amurallado de este asentamiento, se remonta al siglo II a.C. (Santos, Perea y Prados, 1990, 314)

La ciudad de Toletum era en época prerromana centro de un rico territorio en el valle del Tajo y punto estratégico dentro de las comunicaciones en la Meseta Sur. Toledo estaba situado en una zona fértil para el cultivo,lo que nos permite suponer que esta función agrícola había sido la base de su desarrollo en época prerromana. Las primeras referencias históricas acerca de este enclave carpetano, nos describen como en el año 193 a.C. una importante coalición de celtíberos, vacceos y carpetanos fue vencida junto a Toletum $^{3}$. (Livio 35 , 7, 6) En el año 192 a.C. la ciudad es tomada por las tropas romanas dirigidas por M. Fulvio Nobilior. El oppidum carpetano,se asienta en este momento en el mismo emplazamiento de la posterior ciudad romana y de la actual Toledo. Toletum en este período prerromano contaría con un tamaño que oscilaría aproximadamente entre las 40 y 50 hectáreas. (Almagro, 1995, 221) Este asentamiento indígena se convertirá en municipio en época romana, probablemente en época de Augusto. Un autor como Plinio considera a Toledo como cabeza de la Carpetania. Este autor nos indica que los toletani eran estipendiarios del Conventus Carthaginensis. (Plinio NH, 3, 25) Sabemos también de la existencia de una ceca de época republicana con la marca Tole en esta ciudad, lo que nos indica su importancia en este período. Disponemos de varias monedas con la indicación de esta ceca y el tema del jinete ibérico en el reverso. En el anverso junto a la fórmula Ex.s.c. (ex senato cónsulto) figuran nombres indígenas. La coincidencia

3. En esta campaña M. Fulvio, además de vencer al ejército indígena, captura vivo al rey Hilerno. 
de estos nombres indígenas con el tema del jinete y la aparición de la fórmula romana Ex.s.c. ${ }^{4}$ parecen indicar que pudiera tratarse de la emisión de una ceca de la ciudad indígena. (González, 1987, 56)

Una vez que la ciudad alcanza su condición de municipio en época romana se dotará de diversos edificios públicos como un circo,así como algunos puentes sobre el Tajo. En época romana Toletum era una mansión que se encontraba en el cruce de dos vías romanas, la que iba de Emérita a Caesaraugusta y la que desde Laminium alcanzaba Toletum. En este sentido era un lugar estratégico dentro de la Meseta meridional.

Entre los castros carpetanos,el enclave de Consabura (actual Consuegra, Toledo) se encontraba asentado en el Cerro el Calderico y contaba con una superficie aproximada de unas 8 hectáreas. Restos de lo que fue este castro prerromano se localizan parcialmente en este Cerro,especialmente en lo que corresponde a la muralla en sus lados sur y este,de la que parten lo que fueron arranques de viviendas. Este oppidum indígena se convertirá en ciudad romana adquiriendo la condición de municipio. La ciudad se trasladará desde el emplazamiento prerromano a una zona más baja, cercana al río Amarguillo. Plinio en su obra nos cita a Consabura como una ciudad estipendiaria del Conventus Carthaginensis (Plinio, III, 25). Las fuentes históricas mencionan también a esta ciudad dentro de uno de los episodios de las guerras sertorianas. (Frontino Strat. IV, 5, 19) Concretamente sabemos que Sertorio envió a su lugarteniente Hirtuleyo con un ejército, que venció al gobernador de la Citerior M. Domicio Calvino cerca de esta ciudad. De época romana se conservan entre otros, restos de un circo de dimensiones más reducidas al de Toledo y de una presa que era una de las más importantes de Hispania. Consabura era en época romana una cabeza administrativa, que controlaba el territorio próximo. Según el Itinerario de Antonino fue una mansión en la vía romana que unía Laminium con Toletum, aunque este enclave no constituía una encrucijada de vías importantes. En la actualidad está descartada la identificación de Consabura con una ciudad mencionada en la Tesera de Herrera de Pisuerga (Palencia), cuyas similitudes de carácter onomástico apuntan al mundo de la Meseta septentrional.

De algunas ciudades mencionadas en las fuentes históricas como Aebura, no se han hallado hasta la actualidad vestigios arqueológicos. Esta ciudad

4. Esta fórmula no podía indicar la existencia de un Senado en el sentido romano del término, que hubiera significado la presencia de la municipalización sino es identificada con la Libora ptolemaica. (Ptolomeo $2,6,56)$ Sabemos del asentamiento de una guarnición militar romana en esta ciudad en el 181 a.C. (Livio 40, 30, 3) durante la campaña de $Q . F$. Flaco contra los celtíberos. Según el Ravenate Aebu$r a$ se localizaría entre Toletum y Augustobriga.

En el área manchega,dentro de lo que constituye la actual provincia de C. Real, se conocen poblados de menor tamaño y envergadura, parcialmente destruidos por estar situados en zonas húmedas,uno de los cuales es el del Cerro de las Nieves. Este lugar se encuentra al este de la población de Pedro Muñoz. Este poblado se fundó en un momento aún sin precisar, durante el siglo VI o inicios del V a.C. (Fernández, Hornero, Pérez, 1994, 121) La mayoría de los materiales recogidos en este asentamiento son de tipo cerámico, entre los que se pueden distinguir varios tipos: cerámica a torno gris, a torno ibérica,a mano gruesa en vasijas grandes de almacenamiento y a mano fina, en pequeños vasos troncocónicos o bicónicos de tradición de Campos de Vrnas. (Fernández, Hornero, Pérez, 1994, 118) También es importante la presencia en este enclave de fíbulas en bronce y de cerámica griega importada. Entre las actividades económicas que se daban en este asentamiento estarían la agricultura atestiguada por la presencia de hallazgos de morteros, cubetas, etc y la metalurgia en pequeña escala. Otra actividad económica de este asentamiento era la ganadería. Según se desprende de los restos de fauna analizados de-bían predominar los ovicápridos. Este poblado va a ser abandonado hacia fines del siglo IV o inicios del III a.C.

En la zona más oriental de la actual provincia de Ciudad Real, probablemente en la localidad de Alhambra, se localizaba la ciudad romana de Laminium. Este enclave posiblemente había sido un oppidum prerromano,que durante el siglo I d.C. se convertiría en una ciudad privilegiada. Los romanos aprovecharán la existencia de un oppidum ibérico, asimilando a la población indígena, que en el siglo I d.C. estará prácticamente romanizada. El yacimiento de Alhambra se situaba en un cerro de arenisca de $872 \mathrm{mts}$ de altura,que se eleva sobre el Campo de Montiel. Se trataba de un establecimiento de carácter estratégico, que dominaba una vasta extensión geográfica.

Plinio va a incluir a Laminium entre las ciudades estipendiarias del Conventus Carthaginensis. (Plinio III, 25) Este autor va a indicar el nacimiento del Anas en el Ager Laminitanus. (Plinio NH 3, 6) Tam-

más bien la permanencia de las instituciones indígenas como la Asamblea de la ciudad y los magistrados 
bién Plinio nos indica que las mejores piedras de afilar proceden de Laminium. (Plinio, NH, 36, 165) El paso de ciudad stipendiaria a municipio de este enclave se va a producir en época flavia. ${ }^{5}$ Sabemos que en época romana este lugar era un importante nudo de comunicaciones en la $\mathrm{Me}$ seta Sur, tal como nos indica el Itinerario de Antonino. La facilidad de las comunicaciones propiciarían los contactos con otras áreas peninsulares, a juzgar por la presencia de elementos de importación itálicos, vidrios, platos de lujo, etc. También tenemos conocimiento de la existencia de una necrópolis ibero-romana en Laminium. El interés de esta necrópolis reside en su cronología que se inicia en época ibérica y alcanza la romanización. Entre los enterramientos algunos parecen datarse entre los siglos IV-III a.C. (Fernández y Serrano, 1993, 193) Entre los materiales aportados por esta necrópolis destacan diversos unguentarios, 6 urnas pintadas, 1 plato de barniz rojo, 3 platos de terra sigillata aretina y dos esculturas zoomorfas en piedra. (Fernández y Serrano, 1993, 191)

De algunas ciudades carpetanas como Alce, tenemos una referencia por las fuentes históricas que nos informan que esta ciudad fue tomada por T. Sempronio Graco en el 179 a.C. en su campaña contra los celtíberos. Este pueblo estaba en este momento en expansión por zonas como Carpetania,que eran más fértiles que el territorio celtibérico. Graco después de tomar esta ciudad, consiguió un gran botín e hizo prisioneros a los hijos de un reyezuelo llamado Thurro, que a partir de este momento será aliado del ejército romano.(Salinas, 1986, 46) En época romana fue una importante mansión de la calzada que unía Emérita con Caesaraugusta, a través de Lusitania. Según el itinerario de Antonino estaba separada XL m.p. de Laminium y XXIIII de Vico Cuminario. Tradicionalmente se ha querido ubicar en algún lugar de una zona comprendida entre las localidades de Villacañas, Campo de Criptana y Alcazar de S.Juan. (Roldán, 1973, 211) P. Madoz ubica a Alce en la localidad de Alcazar de S. Juan (Madoz, 1846, 443 y 446), donde se ha descubierto una importante villa romana.

La ciudad de Contrebia Cárbica, situada en la la actual localidad conquense de Villasviejas, presenta una importancia que se refleja en el inicio de la conquista romana y en el período de la guerra de Sertorio. En este sentido Livio nos relata los acontecimientos del año 181 a.C. cuando dos legiones romanas marcharon desde Aebura "per Carpetaniam ad Contrebiam”. (Livio 40, 30-34)
Este oppidum prerromano, que contaba con un importante sistema defensivo, parece que tuvo una exténsión aproximada de 45 hectáreas. (Almagro y Dávila, 1995, 212) La localización de Contrebia Cárbica en Fosos de Bayona parece establecerse en función de los hallazgos monetarios de la zona, que han aportado varios testimonios de la ceca Contebacon, identificada con esta ciudad. Konterbia Karbika fue una ciudad que acuñó moneda de plata y bronce desde mediados del siglo II hasta mediados del I a.C. Finalmente debemos indicar que esta ciudad de Contrebia Cárbica parece que va a desaparecer en el siglo I a.C. en favor de la ciudad de Segóbriga, que se hallaba próxima a esta y que alcanzará un importante desarrollo en época altoimperial.Esta ciudad va a estar comunicada con el enclave de Contrebia Cárbica, mediante un ramal de la vía romana Complutum-Cástulo.

De otra parte las necrópolis conocidas de este territorio, como las Esperillas y Villafranca de los Caballeros, reflejan un ambiente plenamente ibérico. La primera de estas necrópolis está emplazada en un pequeño altozano en el término municipal de Sta Cruz de la Zarza (Toledo). El principal rito de enterramiento constatado en esta necrópolis es el de incineración, del que sólo se pueden excluir dos sepulturas de inhumación. Estas tumbas se depositan dentro de cavidades horadadas en la roca caliza. Además de los vasos de ajuar, los enterramientos conservan ofrendas elaboradas en metal. Entre estas piezas se han recogido fíbulas de doble resorte, de ballesta y anulares hispánicas. (García y Martínez, 1988, 63) Esta necrópolis de la II Edad del Hierro tiene un amplio período de utilización que se extiende desde el s.VII hasta el s.III a.C.

De otra parte la necrópolis de Palomar de Pinta-do en el término de Villafranca de los Caballeros (Toledo) presenta un tipo de enterramientos,que como los de carácter tumular,en piedra o adobe, se consideran típicos del área ibérica del S.E. peninsular. Esta necrópolis se caracteriza por la ausencia de cualquier tipo de armas, así como por la presencia de numerosas fíbulas anulares en bronce. También se han hallado en esta ne-crópolis cerámicas de importación como algunos Kántharos áticos de barniz negro. (Carrobles y Ruiz, 1990, 241) El desarrollo de esta necrópolis parece abarcar una amplia cronología que va desde los siglos VII-II a.C. (Carrobles y Ruiz, 1990, 243)

Junto a estas necrópolis, disponemos del hallazgo en un posible conjunto tumbal en el Espartal

5. Algunos testimonios epigráficos (C. I. L. II 3251, 3252) nos confirman este dato. 
(Madrid) de un mango de hueso trabajado,y de un plato de barniz rojo. Estos materiales se sitúan dentro del marco de la segunda edad del Hierro de la Submeseta sur. El plato de barniz rojo sería una muestra de los influjos ibéricos en esta área, mientras que el mango de hueso estaría en relación con la industria ósea realizada por grupos de la II Edad de Hierro en la Meseta Norte. (Barrio y Blasco, 1989)

En definitiva el panorama que nos ofrece el poblamiento en el área carpetana durante época prerromana, es el de un territorio en el que la población se agrupaba generalmente en oppida, ubicados en lugares estratégicos,fácilmente defendibles que controlaban fértiles territorios. Estos asentamientos estaban situados frecuentemente en lugares próximos a cauces fluviales, que ofrecían un importante aprovéchamiento agrícola. La forma del habitat presenta en esta región una continuidad durante toda la edad del Hierro hasta el primer tercio del siglo I a.C.

Las fuentes históricas del período de la conquista, mencionan ciudades que en muchas ocasiones desaparecen o no tienen importancia en el período posterior de control efectivo de Roma del territorio. Sólo ciudades como Complutum, Consabura o Toletum, serán especialmente relevantes en época altoimperial, desarrollando importantes programas urbanísticos, especialmente a partir de época flavia.

\section{Bibliografía}

Abascal, J. M., (1982): Vías de comunicación romanas de la provincia de Guadalajara. Madrid

Alfaro, M. y Martín, A., (1996): "Restos celtibéricos en el término municipal de Redueña (Madrid)" Boletín de la asociación española de amigos de la arqueología, 36, pgs 91-105

Almagro Gorbea, M. y Dávila, A. F., (1989): "Ecce Homo.Una cabaña de la primera edad del Hierro" Revista de Arqueología, pgs 30-38

Almagro Gorbea, M. y DÁvila, A. F., (1995): "El área superficial de los oppida en la Hispania céltica" Complutum, pgs 209-233

ARCE, J., (1980): "La presencia romana en la provincia de Madrid" II Jornadas de estudios sobre la provincia de Madrid, pgs 62-65

Balmaseda, L. J. y Valiente Cánovas, S., (1981): "El relieve de Illescas" AEA 54, pgs 215-238

Blasco Bosqued, M. C., (1986-7): "Paralelos arquitectónicos entre la Meseta Norte y el Alto Tajo durante la II edad del Hierro" Zephyrus, pgs 159-168
-(1992): "Etnogénesis de la Meseta Sur" Complutum 2-3, pgs $281-297$

Blasco Bosqued, M. C. Y Alonso, M. A., (1983): "Aproximación al estudio de la edad del Hierro en la provincia de Madrid" Homenaje al profesor $M$. Almagro Basch. Madrid, pgs 119-134

Blasco Bosqued, M. C. y Alonso, M. A., (1985): Cerro Redondo, Fuente el Saz del Jarama. Madrid

BlasCo, M. C. y BARRIO, J., (1989): "Materiales de la II edad del Hierro procedentes de el Espartal (Madrid)" Cupauam, pgs 233-244

Blasco, M. C. Alonso, Mª ${ }^{\mathrm{a}}$. A. y Valiente, S., (1980): "La edad de Hierro en la provincia de Madrid" II Jor-nadas de estudios sobre la provincia de Madrid, pgs 47-57

BláQuez, J. M., (1986): Ciclos y temas de la Historia de España: La Romanización. Madrid

Caro Baroja, J., (1981): Los pueblos de España. Madrid

Carrobles, J. y Ruiz, G., (1990): "La necrópolis de la edad del Hierro de Palomar de Pintado (Villafranca de los Caballeros, Toledo)" Actas del I Congreso de Arqueología de la Provincia de Toledo, pgs 236-258

Contreras, M., Jiménez, C. y Martín, A., (1993): "Aproximación al estudio de la Mantua Carpetanorum de Ptolomeo. Nuevas aportaciones arqueológicas para su localización" Actas del XXII Congreso Nacional de Arqueología, pgs 399-404

Fernández Galiano, D., (1976): Carta Arqueológica de Alcalá de Henares. Madrid

-(1979): "Informe sobre las excavaciones en Alcalá de Henares" Actas de la IJornada de Estudios sobre la provincia de Madrid, pgs 82-86

Fernández, M. y Serrano, A., (1993): "Una necrópolis iberomana en Laminium (Alhambra, C. Real)" Actas del XXII Congreso Nacional de Arqueología pgs 191-196

Fernández V., Hornero, E. y Pérez, J. A., (1994): “El poblado ibérico del "Cerro de las Nieves"(Pedro Muñoz). Excavaciones 1984-5" Jornadas de Arqueología de C. Real en la Universidad Autónoma de Madrid, pgs 111-129

FITA, F., (1917): "Arganda del Rey. Su nueva inscripción romana.” Brah 71, pgs 349-356

García Carrillo, Amanda A. y Encinas Martínez, M., (1988): "Necrópolis prerromana en Toledo" Revista de Arqueología pgs 62-63

GonZÁlez Conde, M. P., (1987): Romanidad e indigenismo en Carpetania. Alicante.

-(1992): "Los pueblos prerromanos de la Meseta Sur" Complutum 2-3, pgs 299-309 
KNAPP, R. C., (1992): Latin inscripcions from Central Spain. Berkeley

MAdoz, P., (1846): Diccionario geográfico-estadístico-histórico de España y sus posesiones de ultramar. Madrid

Muñoz Carballo, G., (1980): "Castro de la Dehesa de la Oliva II" IIJornadas de Estudios sobre la provincia de Madrid, pgs 57-62

Polo LóPez, J., (1995-6): “Complutum: de la república a los flavios. Una lectura arqueológica de la evolución y transformación del poblamiento en el territorium complutense" Estudios de Prehistoria y Arqueología madrileñas 10, pgs 37-47
Priego Fernández, Ma CARmen, (1980): "El cerro de la Gavia (Vallecas, Madrid)" II Jornadas de estudios sobre la provincia de Madrid, pgs 93-95

Roldán, J. M., (1973): Itineraria Hispana. GranadaValladolid

SALINAS DE FRÍAS, M., (1986): Conquista y romanización de Celtiberia. Salamanca

Urbina, D., (1998): "La Carpetania romana y los carpetanos indígenas: Tribu, etnia, nación o el país de los escarpes" Gerión, 16, pgs 183-208 